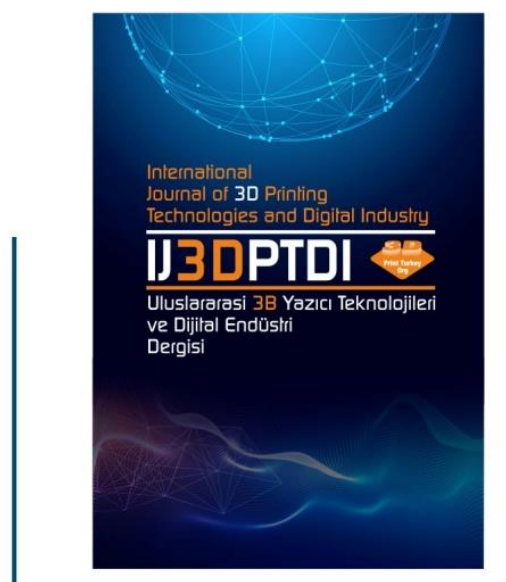

ULUSLARARASI 3B YAZICI TEKNOLOJILERI

VE DIJITAL ENDÜSTRI DERGISI

INTERNATIONAL JOURNAL QF 30 PRINTING TECHNOLOGIES AND DIGITAL INDUSTRY

ISSN:2602-3350 [Online]

URL: https://dergipark.org.tr/ij3dptdi

\title{
ADDITIVELY MANUFACTURED TI6AI4V LATTICE STRUCTURES FOR BIOMEDICAL APPLICATIONS
}

Yazarlar (Authors): Doruk Gürkan®, Binnur Sağbaş® *

Bu makaleye şu şekilde atıfta bulunabilirsiniz (To cite to this article): Gürkan D., Sağbaş B. "Additively Manufactured Ti6Al4V Lattice Structures for Biomedical Applications" Int. J. of 3D Printing Tech. Dig. Ind., 5(2): 155-163, (2021). 


\title{
ADDITIVELY MANUFACTURED TI6AI4V LATTICE STRUCTURES FOR BIOMEDICAL APPLICATIONS
}

\author{
Doruk Gürkan $^{\text {a iD }, \text { Binnur Sağbaşa }}{ }^{\text {iD * }}$ \\ ${ }^{a}$ Yıldız Technical University, Faculty of Mechanical Engineering, Mechanical Engineering Department, \\ ISTANBUL, TURKEY \\ *Corresponding Author: bsagbas@gmail.com
}

(Received: 16.06.2021; Revised: 26.07.2021; Accepted: 04.08.2021)

\begin{abstract}
Additive Manufacturing (AM) is a rapidly developing technology which provides opportunity to build up complex geometries due to the freedom of manufacturing. Lattice structures, three-dimensional opencelled structures composed of one or more repeating unit cells, can be produced with unique mechanical, thermal, acoustic, biomedical and electrical properties by optimization of type and dimension of unit cell and additive manufacturing parameters. Lattice structures provide lightweight and porous parts which are widely preferable in biomedical applications. Different type of lattice structures have been used for obtaining bone like implant surface to accelerate osseointegration. There are many studies in this field, but the ideal designs and dimensional accuracy of the various lattice structures for biomedical field have not been completely reached. In this study, octahedral, star and dodecahedron lattice structures with thin strut diameter were manufactured by laser powder bed fusion technology (LPBF) by Ti6Al4V powder. Cubic and plate samples were built on z-direction and their top and side surfaces were inspected in terms of topographical characteristics and dimensional accuracy by scanning electron microscope. Dimensional accuracy has been found to tend to shrinkage behavior for all lattice structures. The best dimensional accuracy was obtained from octahedral lattice structure comparing with strut diameters.
\end{abstract}

Keywords: Additive Manufacturing. Lattice Structures. Powder Bed Fusion. Ti6Al4V.Orthopedic Prosthesis

\section{INTRODUCTION}

Cellular solids can be grouped as closed-cell foam, open-cell foam, honeycomb and lattice structures. Lattice structures are porous structure form by the arrangement of unit cells making up of struts connecting between two nodes which are rigidly bonded. This affects the useful performance of the building such as mechanical, thermal, acoustic, electrical, biomedical, etc. Lattice structures gives the opportunity of high or lower rigidity, durability, strength, energy absorption rate and thermal protection due to the lattice parameters and lattice topology. Therefore these topologies fulfill lightweight structure and multifunctional requirements for most engineering and biomedical applications [1].

Numerous types of lattice structures are introduced and the basic step in manufacturing lattice structures is building of unit cells in coordinate plane (xyz) [2]. Lattice material is mainly dependent on its internal architecture, relative density, properties of alloy material, strut diameter and length, unit cell geometry, unit cell dimensions and rate of loading. Configuration of struts, strut diameter/length and unit cell orientation with angular aspect lead different lattice geometries with different material properties. Thus, the mechanical properties of lattice structures can be adapted for particular applications for especially biomedical area [3]. It is possible to produce lattice topologies with struts diameter ranging from submicron to millimeter which would permit the production of functional lattice structures based on usage and geometrical requirements for each specific application via rapid development in manufacturing technology and the emergence of additive manufacturing (AM) such as laser powder bed fusion manufacturing [4]. It is not possible with conventional manufacturing technologies or less efficient with them compared to AM technologies. 
Lattice structures can be classified in various ways such as random or periodic, 2D or 3D, open or closed, homogeneous or heterogeneous [5]. The most specific types are strut-based and triply periodic minimal surfaces (TPMS). Strut-based lattices have the unit cells which are composed of a set of strut beams interconnected with each other in points. TPMS topologies have porous and zero mean curvature of the surface. Their topologies are formed by some mathematical equations [6]. Some unit cell lattice structures are shown in Figure 1 (1x1x1 mm, xyz).

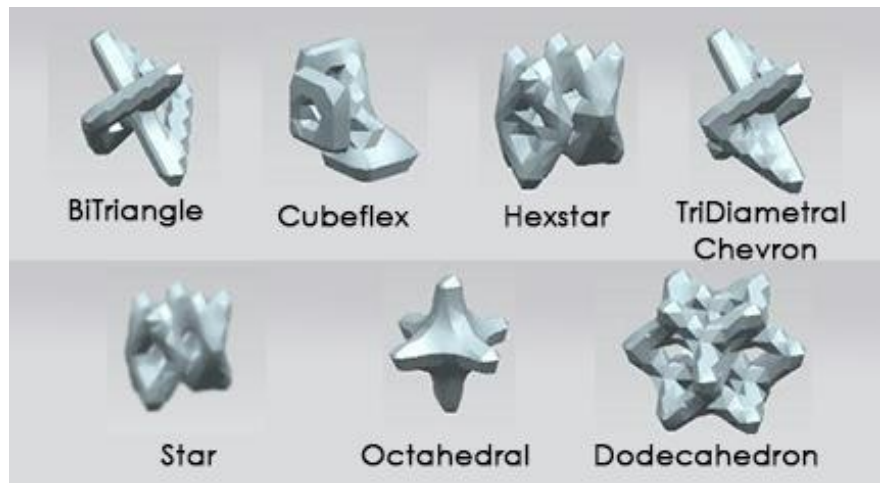

Figure 1. Some lattice structures as a unit cell $(1 \mathrm{x} 1 \mathrm{x} 1 \mathrm{~mm}, \mathrm{xyz})$.

AM allows creation of very complex shapes as opposed to the conventional methods of subtractive manufacturing and provides almost unchallenged freedom of design [7]. Ti6Al4V is an alloy that has widespread application in the engineering, surgical and biomedical industries and has become a reference metallic material in ASTM standards due to its unique mechanical and biocompatible properties [8]. Ti6Al4V has high corrosion resistance, high strength and biocompatibility combined with low density and thermal conductivity [9]. These properties are suitable for biomedical applications. Many studies have focused on optimizing the additive manufacturing to produce dense Ti6A14V parts, but recently great emphasis has been placed on producing low density Ti6Al4V lattice structures for engineering and biomedical applications because of its bearings and multifunctional properties such as bone implant usage [10]. The most challenging phenomenon in bone implant implementation is issue of stress shielding effect (elastic modulus miss-match phenomenon between Ti implant and the bone tissue) [11]. Stress shielding causes to implant failure and this phenomenon is occurred due to replacing damaged bone tissues of low elastic modulus with dense Ti6Al4V alloy which has a high elastic modulus $(110 \mathrm{GPa})$. Biometric structures such as lattice structures of low elastic modulus (7.7 - 21.8 GPa) are suitable to resolve the mismatching problem. The alternative of lattice structure depends on the desired purpose e.g. bone implants, femoral stems, dental implants, bone tissues, etc. AM technology leads to produce porous structures and it is crucial for bone regeneration for biomedical implants. Porous structures also help to resolve stress shielding effect [12].

Recently, porous and lattice structures have been commonly used in biomedical applications. AM technologies ensure high porosity which can enhance osseointegration, ease bone ingrowth and regeneration and stability over lattice structures. Arabnejad et al. [13] reported that Ti6Al4V porous implants could give advantage in bone ingrowth of up to 56\%. Pobloth et al. [14] revealed that bone regeneration of porous Ti scaffolds could be enhanced with low stiffness via animal study. Wally et al. [15] produced graded porous Ti6Al4V lattice structures for dental applications. Tu et al. [16] reported that usage of bioactive porous dental implant and evaluation of its osseointegration using in vivo tests. Geometrical and topological parameters of lattice structures such as relative density, pore size and connectivity are key factors for the design of biomedical implants with acceptable biological and mechanical properties [17]. Ti6Al4V lattice topologies allow low effective elastic modulus closer to the human bone in structure. Even though smaller pore size distribution such as $300-400 \mu \mathrm{m}$ range has been reported to be more appropriate than bigger pore size distribution such as $400-500 \mu \mathrm{m}$ and $500-700 \mu \mathrm{m}$ range for bone cell adhesion and proliferation $[18,19]$. Inadequate lattice parameters can affect the surface texture and final output. Moreover, build orientation can affect gas hole formation and fusion defects in structure and these cause the inner defect formation [20]. In addition, the heat flow efficiency 
during the manufacturing stage causes to promote a better surface texture at lower angles [21]. Yan et al. [22] designed SLM isotropic Ti6Al4V ELI octahedral lattice structures in their study and then investigated their use for human bone implant applications. Ahmadi et al. [23] studied mechanical properties of diamond lattice structures. Lattice mechanical properties of structure was affected with build orientation. It was reported that the horizontal struts of lattice structures had the worst dimensional accuracy and internal porosity quality. This situation caused poor mechanical properties. Some authors focused on topographic analysis on lattice structures. Calignano et al. [24] had demonstrated that the .STL file had an influence on the dimensional accuracy. Delago et al. [25] showed notable variance between CAD models and SLM produced geometry. Some part of samples had additional material in lattice structure and insufficient of material in others. Kadirgama et al. [26] showed that volume of lattice structures which they produced were expanded by $2.9 \%$ comparing to original CAD data.

In this paper, the feasibility of manufacturing of star, dodecahedron and octahedral lattice structures, with thin strut diameter by laser powder bed fusion technology, was searched for biomedical applications. Ti6Al4V samples were manufactured in cube and plate form. Topographical and dimensional analysis on top and side surfaces of the samples were applied and the results were compared between three different lattice structures.

\section{MATERIALS AND METHODS}

Gas atomized, Ti6Al4 powder (EOS, EOS GmbH, Germany) was used as the feedstock material for building up samples. The chemical composition of the Ti6Al4V alloy powder was listed in Table 2. The Ti6Al4V samples were manufactured by EOS M280 system (EOS GmbH, Germany). The process parameters, used for manufacturing the samples were as follows: $150 \mathrm{~W}$ laser power, $1250 \mathrm{~mm} / \mathrm{s}$ scanning speed, $60 \mu \mathrm{m}$ layer thickness and $40 \mu \mathrm{m}$ hatch distance.

Table 1. The chemical composition of the used Ti6Al4V powder (EOS) [27].

\begin{tabular}{ccccccccc}
\hline $\mathbf{T i}(\boldsymbol{\%})$ & $\mathbf{A l}(\boldsymbol{\%})$ & $\mathbf{V}(\boldsymbol{\%})$ & $\mathbf{F e}(\boldsymbol{\%})$ & $\mathbf{O}(\boldsymbol{\%})$ & $\mathbf{N}(\boldsymbol{\%})$ & $\mathbf{C}(\boldsymbol{\%})$ & $\mathbf{H}(\boldsymbol{\%})$ & $\mathbf{Y}(\boldsymbol{\%})$ \\
\hline 88 & 6.75 & 4.5 & 0.3 & 0.2 & 0.05 & 0.08 & 0.015 & 0.05 \\
\hline
\end{tabular}

The design of lattice structures were achieved using Siemens NX version 12.0 (Siemens AG, Germany). Star, dodecahedron and octahedral lattice structures were manufactured as $0.25 \mathrm{~mm}$ strut diameter. Unit cell dimension was chosen as $1.25 \times 1.25 \times 1 \mathrm{~mm}$ (xyz) as can be seen in Figure 2. All cubic samples were manufactured as 10x10x10 mm like as a compression test samples according to ISO 13314 [28]. Plate samples were manufactured in 8x10x2 mm. Both samples were built on z-direction. A $2 \mathrm{~mm}$ support structure was used to carry out the sample fabrication and to ensure the separation of samples from the building plate without damaging the lattice structures. The parts were separated from the support structures by wire erosion method. In some SLM systems such structures are added to the part design in the production of strut-based lattice structures. The fact that the curved cell surface is not in the selected strut-based structures that this situation is necessary [29, 30]. In addition, the lattice samples are prevented from deformation via touching the building platform in this way.

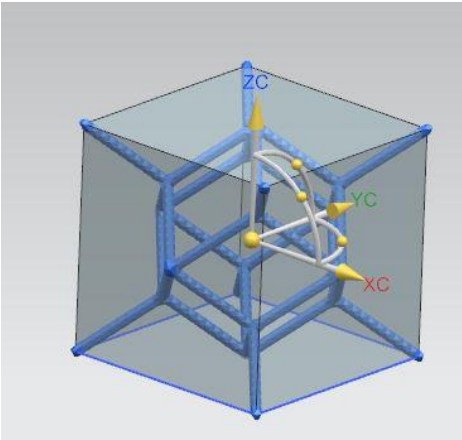

(a)

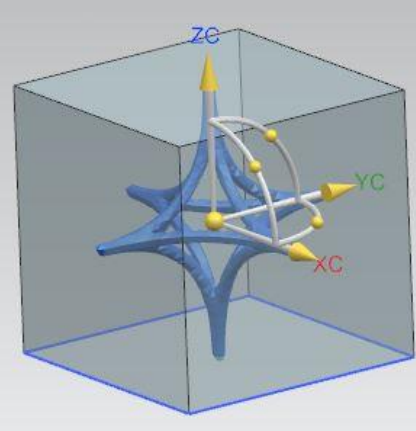

(b)

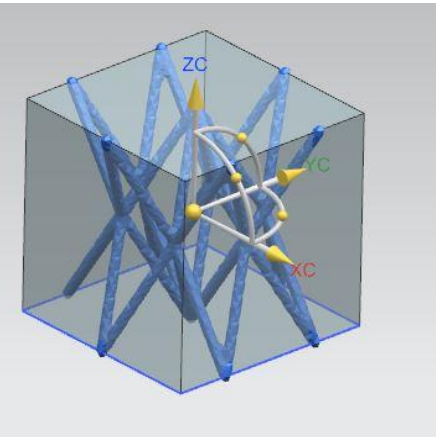

(c)

Figure 2. Unit cells; (a) dodecahedron, (b) octahedral and (c) star. Unit cell size and strut diameter were chosen as $1.25 \times 1.25 \times 1 \mathrm{~mm}(\mathrm{xyz})$ and $0.25 \mathrm{~mm}$. 
Topographic analysis on top and side surfaces of the samples were applied by Zeiss EVO LS 10 (Zeiss, UK) scanning electron microscope (SEM) by secondary electron detector with different magnifications. Dimensional measurements were taken from different regions of the surfaces and their mean values were reported.

\section{RESULTS AND DISCUSSION}

Manufactured samples with their support structures can be seen in Figure 3. The non-stochastic configuration that caused any problems was not seen during production.
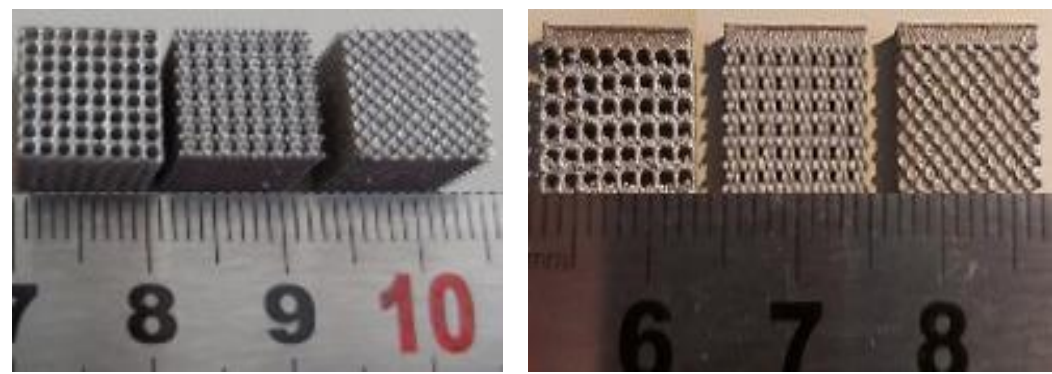

Figure 3. Manufactured parts on building platform (left, cubic samples; right, plate samples).

Topographical measurements were taken from top and side surfaces which were represented in Figure 4. Top surface measurements were taken from top surface of the cubic samples while side surface measurements were taken from plate samples as shown in Figure 4. At least 5 measuring points were selected on different regions of surfaces for all selected lattice parameter values.

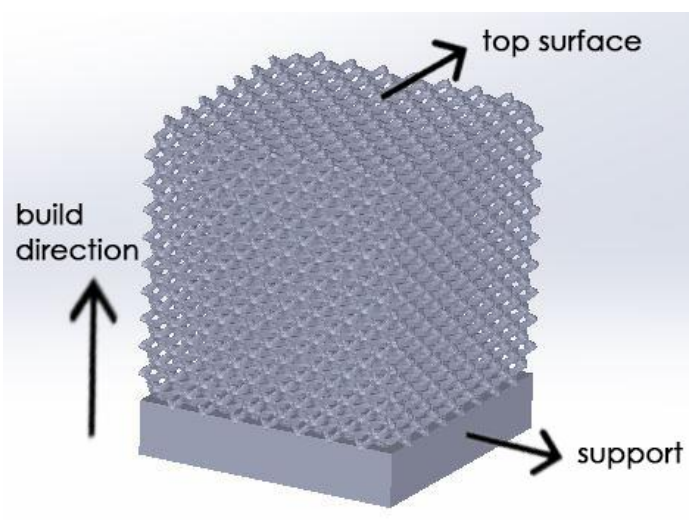

(a)

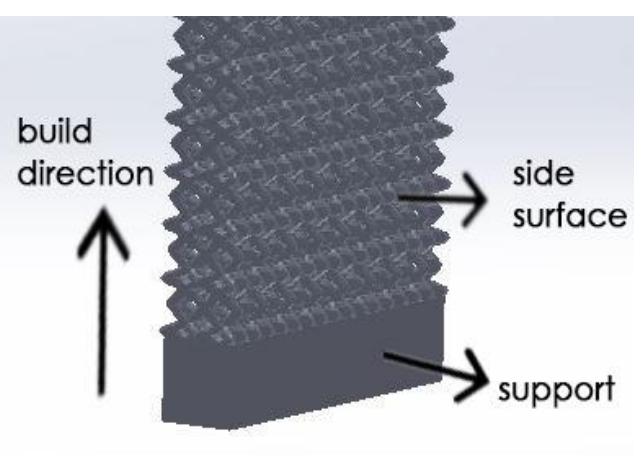

(b)

Figure 4. Measurement obtained method from lattice samples (a) cubic (b) plate.

SEM images of the octahedral lattice structure sample can be seen in Figure 5 on which measured dimensions of the lattice structure were indicated. $t$ represents dimension of lattice pores and d represents strut diameter. To define mean value of the dimensions, measurements were taken from different region of the surfaces. Nominal dimensions (n), defined in CAD model and the mean values $(\mathrm{m})$ of measured results were reported in Table 2. It was clear from the results that negative deviation of the pore size was recorded on side surface while positive deviations were recorded for strut diameters of both surfaces. 


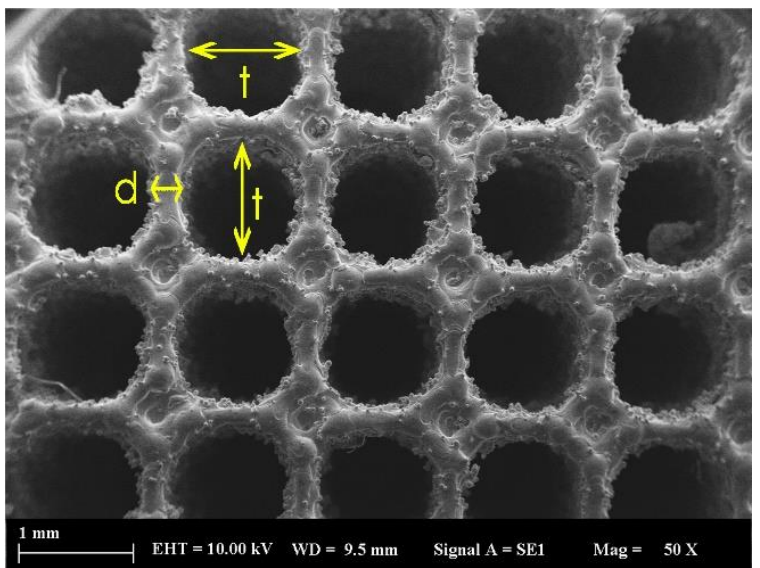

(a)

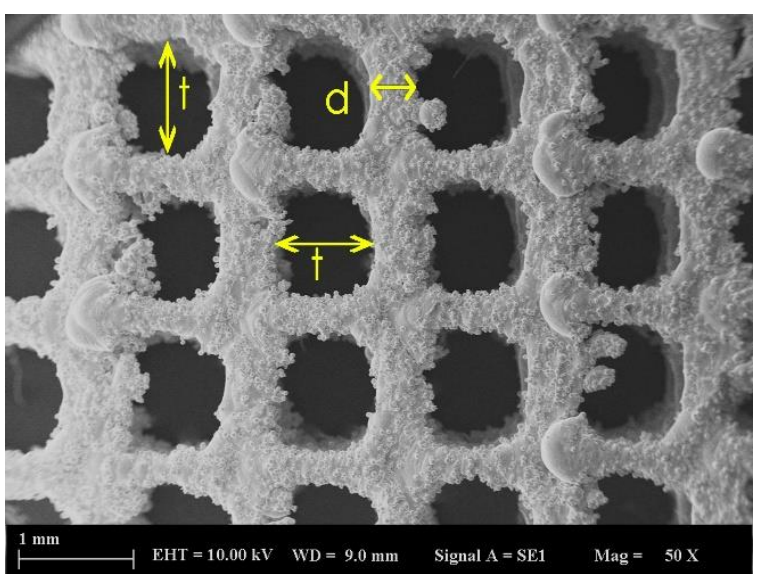

(b)

Figure 5. Octahedral lattice structure (a) top surface (b) side surface.

Table 2. Octahedral lattice structure dimension data

\begin{tabular}{lcccccc}
\hline Octahedral & $\mathrm{t}_{\mathrm{n}}(\mathrm{mm})$ & $\mathrm{t}_{\mathrm{m}}(\mathrm{mm})$ & $\begin{array}{c}\text { Deviation } \\
(\mathrm{mm})\end{array}$ & $\mathrm{d}_{\mathrm{n}}(\mathrm{mm})$ & $\begin{array}{c}\mathrm{d}_{\mathrm{m}} \\
(\mathrm{mm})\end{array}$ & $\begin{array}{c}\text { Deviation } \\
(\mathrm{mm})\end{array}$ \\
\hline Top surface & 1 & 1.0285 & +0.0285 & 0.25 & 0.2679 & +0.0179 \\
Side surface & 1 & 0.9557 & -0.0443 & 0.25 & 0.2698 & +0.0178 \\
\hline
\end{tabular}

$t_{n}$ : nominal dimension of $t$ value, $t_{m}$ : mean value of measured $t, d_{n}$ : nominal dimension of $d$ value, $d_{m}$ : mean value of measured $d$.

SEM images and measurement results of the star lattice structure can be seen in Figure 6 and Table 3 respectively. $\mathrm{u}$ and $\mathrm{v}$ represent lattice pore length and width respectively and e represents vertical distance of outer pore edges. Although negative deviations were measured for both surfaces, except lattice pore width, values of these deviations were higher on side surface than top surface.

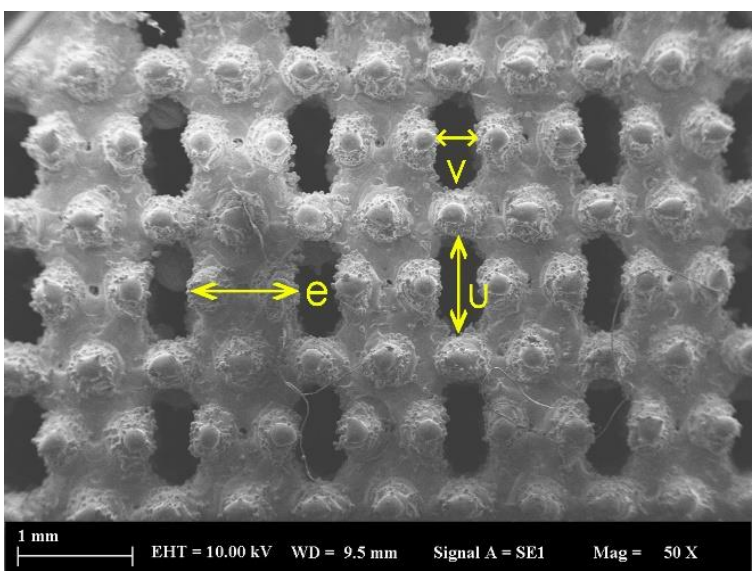

(a)

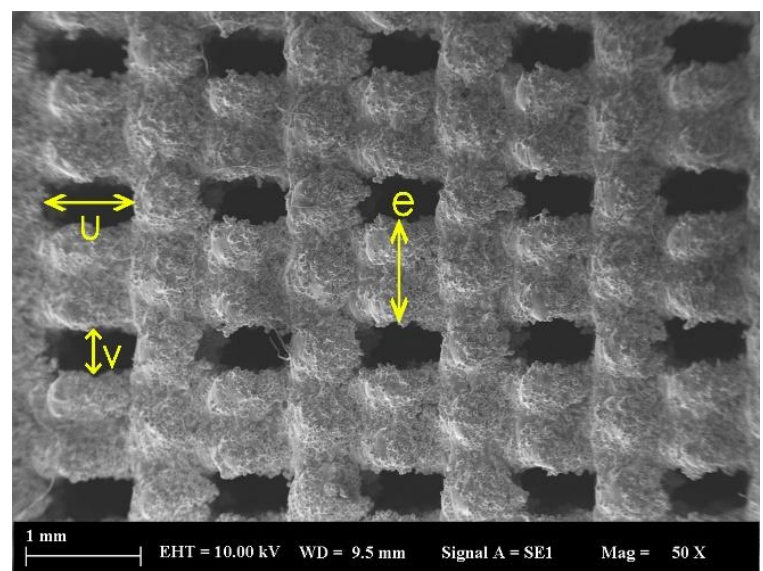

(b)

Figure 6. Star lattice structure (a) top surface (b) side surface.

Table 3. Star lattice structure dimension data

\begin{tabular}{cccccccccc}
\hline Star & $\begin{array}{c}\mathrm{u}_{\mathrm{n}} \\
(\mathrm{mm})\end{array}$ & $\begin{array}{c}\mathrm{u}_{\mathrm{m}} \\
(\mathrm{mm})\end{array}$ & $\begin{array}{c}\text { Deviation } \\
(\mathrm{mm})\end{array}$ & $\begin{array}{c}\mathrm{v}_{\mathrm{n}} \\
(\mathrm{mm})\end{array}$ & $\begin{array}{c}\mathrm{v}_{\mathrm{m}} \\
(\mathrm{mm})\end{array}$ & $\begin{array}{c}\text { Deviation } \\
(\mathrm{mm})\end{array}$ & $\begin{array}{c}\mathrm{e}_{\mathrm{n}} \\
(\mathrm{mm})\end{array}$ & $\begin{array}{c}\mathrm{e}_{\mathrm{m}} \\
(\mathrm{mm})\end{array}$ & $\begin{array}{c}\text { Deviatio } \\
\mathrm{n}(\mathrm{mm})\end{array}$ \\
\hline $\begin{array}{c}\text { Top } \\
\text { surface }\end{array}$ & 0.9 & 0.8423 & -0.0577 & 0.375 & 0.3792 & +0.0042 & 0.875 & 0.8313 & $-0,0437$ \\
$\begin{array}{c}\text { Side } \\
\text { surface }\end{array}$ & 0.9 & 0.8329 & -0.0671 & 0.375 & 0.3953 & +0.0203 & 0.875 & 0.8254 & -0.0496 \\
\hline
\end{tabular}

$u_{n}$ : nominal dimension of $u$ value, $u_{m}:$ mean value of measured $u, v_{n}:$ nominal dimension of value, $v_{m}:$ mean value of measured $v, e_{n}$ : nominal dimension of e value, $e_{m}$ : mean value of measured $e$.

SEM images and measurement results of the dodecahedron lattice structure can be seen in Figure 7 and Table 4 respectively. In this figure, $\mathrm{d}$ represents strut diameter where $\mathrm{f}$ represents unit cell diagonal 
length and g represents nominal inner lattice pore diameter. Negative deviations were recorded for strut diameter on both surfaces like as unit cell diagonal length. Positive deviation were recorded for pore diameter on top surface while it was negative on side surface.

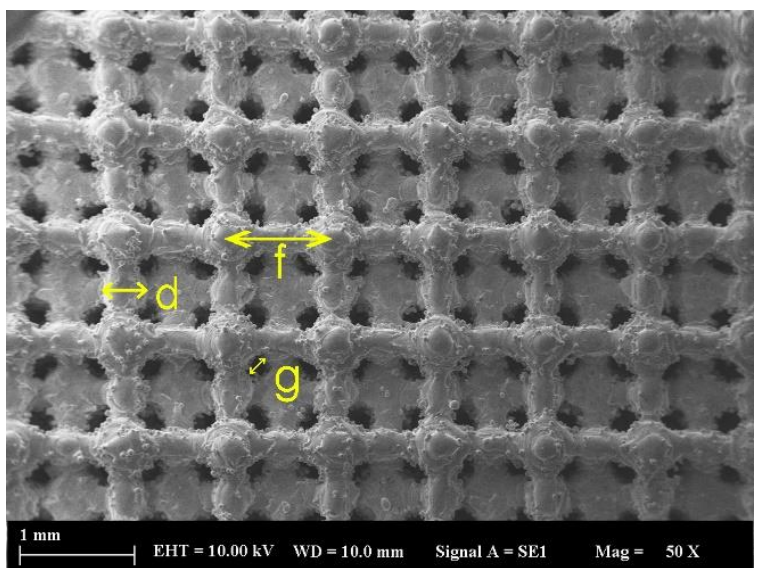

(a)

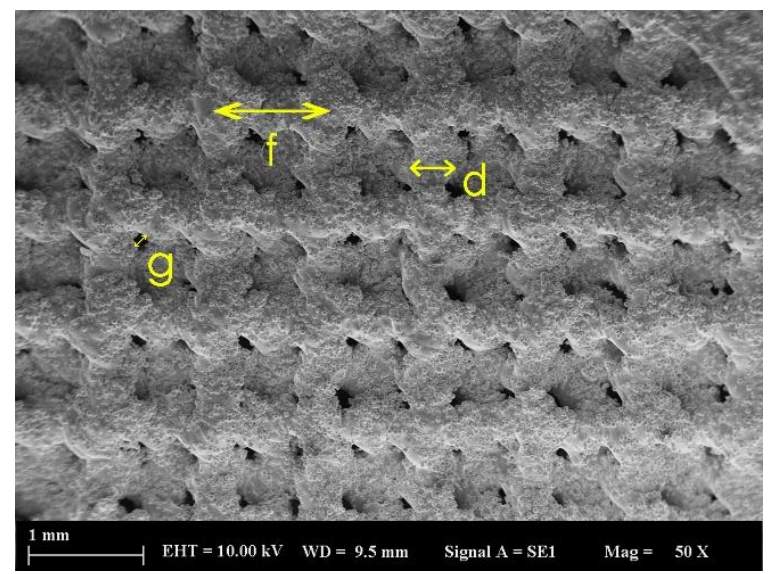

(b)

Figure 7. Dodecahedron lattice structure (a) top surface (b) side surface.

Table 4. Dodecahedron lattice structure dimension data

\begin{tabular}{cccccccccc}
\hline Dodecahedron & $\begin{array}{c}\mathrm{d}_{\mathrm{n}} \\
(\mathrm{mm})\end{array}$ & $\begin{array}{c}\mathrm{d}_{\mathrm{m}} \\
(\mathrm{mm})\end{array}$ & $\begin{array}{c}\text { Deviation } \\
(\mathrm{mm})\end{array}$ & $\begin{array}{c}\mathrm{f}_{\mathrm{n}} \\
(\mathrm{mm})\end{array}$ & $\begin{array}{c}\mathrm{f}_{\mathrm{m}} \\
(\mathrm{mm})\end{array}$ & $\begin{array}{c}\text { Deviation } \\
(\mathrm{mm})\end{array}$ & $\begin{array}{c}\mathrm{g}_{\mathrm{n}} \\
(\mathrm{mm})\end{array}$ & $\begin{array}{c}\mathrm{g}_{\mathrm{m}} \\
(\mathrm{mm})\end{array}$ & $\begin{array}{c}\text { Deviation } \\
(\mathrm{mm})\end{array}$ \\
\hline Top surface & 0.25 & 0.2166 & $-0,0334$ & 1 & 0.9327 & -0.0673 & 0.2 & 0.2053 & +0.0530 \\
Side surface & 0.25 & 0.2234 & -0.0266 & 1 & 0.9551 & -0.0449 & 0.2 & 0.1735 & -0.0265 \\
\hline \multicolumn{7}{c}{ : nominal dimension of $d$ value, $d_{m}$ : mean value of measured $d, f_{n}:$ nominal dimension of $f$ value, $f_{m}:$ mean value of } \\
measured $f, g_{n}:$ nominal dimension of $g$ value, $g_{m}:$ mean value of measured $g$.
\end{tabular}

Figure 8 shows remained powder particles on side surface of lattice structures. Side surfaces had more remain powder particles due to contact with the overhang during manufacturing process. This effect occurs layer-by-layer building. During manufacturing, powders are still sintered and heated every layer lay out and down layer of the struts leads to a dross formation on recent surface which decreases dimensional accuracy [31].

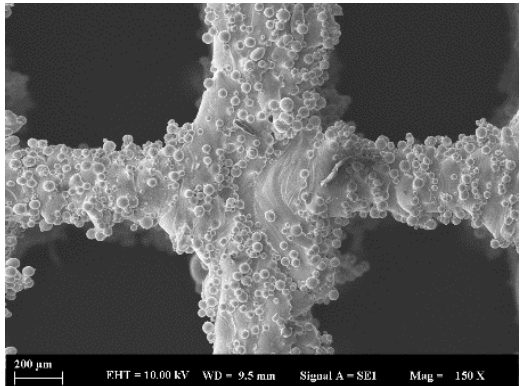

(a)

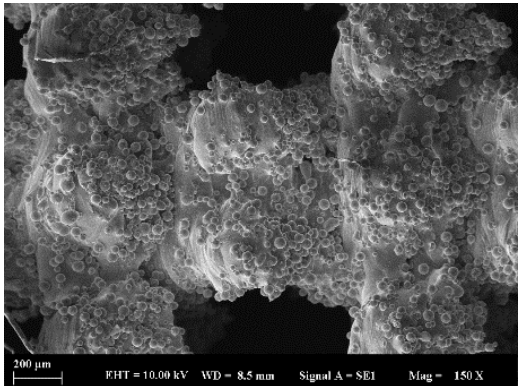

(b)

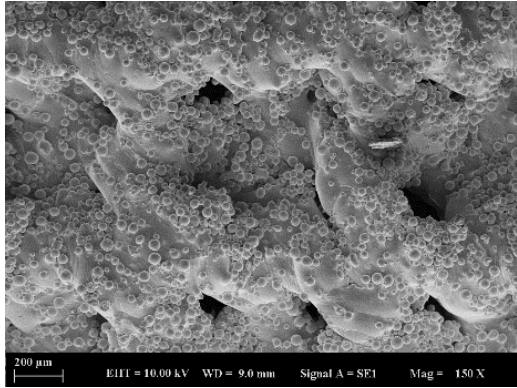

(c)

Figure 8. Remain powder particles on (a) octahedral, (b) star and (c) dodecahedron lattice structures

Topographic analysis showed that there were mostly shrinkage on lattice dimensions which may be related to lattice topology. From literature, it can be found that the dimensional accuracy of additive manufactured parts are affected from shrinkage as a dominant factor [32]. However studies about the prediction of shrinkage level is lacking in literature. It might said that various lattice topologies affect shrinkage ratio. In this study octahedral lattice structure had minimum shrinkage ratio according to experimental data.

\section{CONCLUSION}

Geometrical considerations such as strut diameter/thickness and unit cell size affect resulting lattice topology of the implant. This study reported dimensional deviations on top and side surfaces of three 
different lattice structures such as octahedral, star and dodecahedron manufactured by laser powder bed fusion technology from Ti6Al4V powders. It can be concluded that,

- Lattice structures with very low strut diameter can be successfully manufactured by SLM.

- The top surfaces (parallel to building platform) had smoother and better finish compared to the side surfaces (normal to the building platform). Side surface had more remained powder particles due to contact with the overhang during manufacturing process. Remained powders hanged at near edges much more because of unmelted powder layers in SLM process.

- Comparing with strut diameters, the best dimensional accuracy obtained from octahedral lattice structure. Latter was dodecahedron lattice structures. Star lattice structure values were less then these two samples. Top surface measurements showed that better dimensional accuracy was achieved than side surfaces.

- Dimensions of lattice structures were found to be smaller than the nominal CAD values which may aroused by shrinkage of the material during solidification.

- In further studies beside dimensional accuracy, mechanical strength and microstructural analysis will be applied on these lattice structures with different lattice parameters.

\section{ACKNOWLEDGE}

This work was supported by Yildiz Technical University Scientific Research Projects Coordination Unit. Project Number: FDK-2021-4135.

\section{REFERENCES}

1. Tao, W., Leu, M.C., "Design of lattice structure for additive manufacturing", International Symposium on Flexible Automation (ISFA), Pages 325-332, Cleveland, 2016.

2. Pan, C., Han, Y., Lu, J., "Design and Optimization of Lattice Structures: A Review", Applied Sciences, Vol. 10, Issue 18, 6374, 2020.

3. Abdulhadi, H.S., Mian, A., "Effect of strut length and orientation on elastic mechanical response of modified body-centered cubic lattice structures", Proceedings of the Institution of Mechanical Engineers, Part L Journal of Materials Design and Applications, Vol. 233, Issue 11, Pages 2219-2233, 2019.

4. Sing, S.L., Yeong, W.Y., "Laser powder bed fusion for metal additive manufacturing: perspectives on recent developments", Virtual and Physical Prototyping, Vol. 15, Issue 3, Pages 359-370, 2020.

5. Riva, L., Ginestra, P.S., Ceretti, E., "Mechanical characterization and properties of laser-based powder bedfused lattice structures: a review", The International Journal of Advanced Manufacturing Technology, Vol. 113, Pages 649-671, 2021.

6. Jin, Y., Kong, H., Zhou, X., Li, G., Du, J., "Design and Characterization of Sheet-Based Gyroid Porous Structures with Bioinspire Functional Gradients”, Materials, Vol. 13, Issue 17, 3844, 2020.

7. Weller, C., Kleer, R., Piller, F.T., "Economic Implications of 3D printing: Market structure Models in light of additive manufacturing revisited", International Journal of Production Economics, Vol. 164, Pages 43-56, 2015.

8. Ali, S., Abdul Rani, A.M., Baig, Z., Ahmed, S.W., Hussain, G., Subramaniam, K., Hastuty, S., Rao, TVVLN., "Biocompatibility and corrosion resistance of metallic biomaterials", Corrosion Reviews, Vol. 38, Issue 5, Pages 381-402, 2020. 
9. Kayacan, M., Delikanlı, Y., Duman, B., Özsoy, K., “Ti6Al4V toz alaşımı kullanılarak sls ile üretilen geçişli (değişken) gözenekli numunelerin mekanik özelliklerinin incelenmesi”, Gazi Üniversitesi Mühendislik Mimarlık Fakültesi Dergisi, Vol. 33, Issue 1, Pages 0-0, 2018.

10. Li, X., Wang, C., Zhang, W., Li, Y., "Fabrication and compressive properties of Ti6Al4V implant with honeycomb-like structure for biomedical applications”, Rapid Prototyping Journal, Vol. 16, Issue 1, Pages 44-49, 2010.

11. Sumner, D.R., "Long-term implant fixation and stress-shielding in total hip replacement", Journal of Biomechanics, Vol. 48, Issue 5, Pages 797-800, 2014.

12. Li, Y., Yang, C., Zhao, H., Qu, S., Li, X., Li, Y., "New Developments of Ti-Based Alloys for Biomedical Applications”, Materials, Vol. 7, Issue 3, Pages 1709-1800, 2014.

13. Arabnejad, S., Johnston, R.B., Pura, J.A., Singh, B., Tanzer, M., Pasini, D., "High-strength porous biomaterials for bone replacement: A strategy to assess the interplay between cell morphology, mechanical properties, bone ingrowth and manufacturing constraints", Acta Biomaterialia, Vol. 30, Pages 345-356, 2016.

14. Pobloth, A.M, Checa, S., Razi, H., Petersen, A., Weaver, J.C., Schmidt-Bleek, K., Windolf, M., Tatai, A.A., Roth, C.P., Schaser, K.D., Duda, G.N., Schwabe, P., "Mechanobiologically optimized 3D titanium-mesh scaffolds enhance bone regeneration in critical segmental defects in sheep", Science Translition Medicine, Vol. 10, Issue 423, eaam8828, 2018.

15. Wally, Z.J., Haque, A.M., Feteira, A., Claeyssens, F., Goodall, R., Reilly, C., "Selective laser melting processed Ti6Al4V lattices with graded porosities for dental applications", Journal of the Mechanical Behavior of Biomedical Materials, Vol. 90, Pages 20-29, 2019.

16. Tu, C.C., Tsai, P.I., Chen, S.Y., Kuo, M.Y.P., Sun, J.S., Chang, J.Z.C., “3D laser-printed porous Ti6Al4V dental implants for compromised bone support”, Journal of the Formosan Medical Association, Vol. 119, Issue 1, Part 3, Pages 420-429, 2020.

17. Maconachie, T., Leary, M., Lozanovski, B., Zhang, X., Qian, M., Faruque, O., Brandt, M., "SLM lattice structures: Properties, performance, applications and challenges", Materials \& Design, Vol. 183, 108137, 2019.

18. Tilton, M., Borjali, A., Isaacson, A., Varadarajan, K.M., Manogharan, G.P., "On structure and mechanics of biomimetic meta-biomaterials fabricated via metal additive manufacturing” Materials \& Design., Vol. 201, 109498, 2021.

19. Li, G., Wang, L., Pan, W., Yang, F., Jiang, W., Wu, X., Kong, X., Dai, K., Hao, Y., "In vitro and in vivo study of additive manufactured porous Ti6Al4V scaffolds for repairing bone defects", Scientific Reports, Vol. 6, Issue 1, Pages 1-11, 2016.

20. Echeta, I., Feng, X., Dutton, B., Leach, R., Paino, S., "Review of defects in lattice structures manufactured by powder bed fusion", The International Journal of Advanced Manufacturing Technology, Vol. 106, Issue 5, Pages 2649-2668, 2020.

21. Leach, R., Carmignato, S., "Precision Metal Additive Manufacturing”, Page 143, CRC Press, Florida, 2021.

22. Yan, X., Li, Q., Yin, S., Chen, Z., Jenkins, R., Chen, C., Wang, J., Ma, W., Bolot, R., Lupoi, R., Ren, Z., Liao, H., Liu, M., "Mechanical and in vitro study of an isotropic Ti6Al4V lattice structure fabricated using selective laser melting", Journal of Alloys and Compounds, Vol. 782, Pages, 209-223, 2019. 
23. Ahmadi, S.M., Yavari, S.A., Wauthle, R., Pouran, B., Schrooten, J., Weinans, H., Zadpoor, A.A., "Additively manufactured open-cell porous biomaterials made from six different space-filling unit cells: The mechanical and morphological properties”, Vol. 8, Issue 4, Pages 1871-1896, 2015.

24. Calignano, F., Lorusso, M., Pakkanen, J., Trevisan, F., Ambrosio, E.P., Manfredi, D., Fino, P., "Investigation of accuracy and dimensional limits of part produced in aluminum alloy by selective laser melting" The International Journal of Advanced Manufacturing Technology, Vol. 88, Issue 1-4, Pages 451458, 2017.

25. Dallago, M., Zanini, F., Carmignato, S., Pasini, D., Benedetti, M., "Effect of the geometrical defectiveness on the mechanical properties of SLM biomedical Ti6Al4V lattices", Procedia Structural Integrity, Vol. 13, Pages 161-167, 2018.

26. Kadirgama, K., Harun, W.S.W., Tarlochan, F., Samykano, M., Ramasamy, D., Azir, M.Z., Mehboob, H., "Statistical and optimize of lattice structures with selective laser melting (SLM) of Ti6AL4V material", The International Journal of Advanced Manufacturing Technology, Vol 97, Issue 1, Pages 495-510, 2018.

27. EOS, “EOS Titanium Ti64 data sheet”, http://www.eos.info, March 30, 2021.

28. International Organization for Standardization, "ISO 13314 Mechanical testing of metals, ductility testing, compression test for porous and cellular metals”, Reference Number ISO. 13314 (2011), Pages 1-7, 2011.

29. Ma, S., Tan, Q., Feng, Q., Song, J., Han, X., Guo, F., "Mechanical behaviours and mass transport properties of bone-mimicking scaffolds consisted of gyroid structures manufactured using selective laser melting", Journal of the Mechanical Behavior of Biomedical Materials, Vol. 93, Pages 158-169, 2019.

30. Yan, C., Hao, L., Hussein, A., Young, P., Raymond, D., “Advanced lightweight 316L stainless steel cellular lattice structures fabricated via selective laser melting”, Materials \& Design, Vol. 55, Pages 533-541, 2014.

31. Kamat, A.M., Pei, Y., "An analytical method to predict and compensate for residual stress-induced deformation in overhanging regions of internal channels fabricated using powder bed fusion", Additive Manufacturing, Vol. 29, 100796, 2019.

32. Zhu, H.H., Lu, L., Fuh, J.Y.H., "Study on Shrinkage Behaviour of Direct Laser Sintering Metallic Powder", Proceedings of the Institution of Mechanical Engineers, Part B: Journal of Engineering Manufacture, Vol. 220, Issue 2, Pages 183-190, 2006. 